\title{
Herpesvírus bovinos (BoHV-1.1 e BoHV-1.2b) em forma infecciosa em encéfalos de bovinos submetidos ao diagnóstico de raiva no estado do Rio Grande do Sul
}

\author{
[Bovine herpesviruses (BoHV-1 and BoHV-1.2b) in infectious form in brains of cattle submitted to rabies \\ diagnosis in the State of Rio Grande do Sul, Brazil] \\ H.B.C.R. Batista ${ }^{1}$, E. Schmidt ${ }^{2}$, F.R. Spilki ${ }^{3}$, A.C. Franco ${ }^{1}$, P.M. Roehe $e^{1,2}$ \\ ${ }^{1}$ Departamento de Microbiologia - ICBS-UFRGS - Porto Alegre, RS, \\ ${ }^{2}$ IPVDF-FEPAGRO - Saúde Animal - Eldorado do Sul, RS \\ ${ }^{3}$ Instituto de Ciências da Saúde - FEEVALE - Novo Hamburgo, RS
}

\begin{abstract}
RESUMO
Verificou-se a incidência de herpesvírus bovinos (BoHVs) em encéfalos de bovinos submetidos ao diagnóstico de raiva no estado do Rio Grande do Sul. Para tanto, amostras coletadas durante dois anos $(\mathrm{n}=70)$ foram submetidas ao isolamento viral em cultivos celulares. Os BoHVs foram isolados em dois $(2,9 \%)$ encéfalos. Após serem submetidas à caracterização antigênica e molecular, as amostras foram subtipadas como BoHV-1.1 e BoHV-1.2b. A BoHV-1.1 foi isolada de um encéfalo que foi também positivo para raiva. $\mathrm{O}$ vírus da raiva foi identificado em 11 amostras (15,7\%). Estes achados revelam que a incidência de BoHVs em forma infecciosa em bovinos com encefalite foi baixa, embora represente $16,7 \%$ (2/12) dos encéfalos nos quais um agente viral foi identificado. Tal fato confirma a já reportada associação entre BoHV-1 e encefalites. Esse é o primeiro relato da ocorrência de BoHV-1.2b, um subtipo considerado menos patogênico, em um caso de doença neurológica em bovinos.
\end{abstract}

Palavras-chave: herpesvírus bovino-1, BoHV-1, BoHV-1.2b, raiva, encefalite

\begin{abstract}
The incidence of bovine herpesviruses (BoHVs) was determined in brains of cattle submitted to rabies diagnosis in the State of Rio Grande do Sul, Brazil. Brain samples collected in a two-year interval $(n=70)$ were submitted to virus isolation in cell culture. The BoHVs were isolated from two (2.9\%) of the brains. After the antigenic and molecular characterization, the isolated strains were subtyped as BoHV-1.1 and BoHV-1.2b. The BoHV-1.1 isolate was recovered from a brain sample that was also positive for rabies. Rabies virus was identified in $11(15.7 \%)$ samples. These findings reveal that the incidence of infectious BoHVs in brains of cattle with encephalitis was low, although these represented $16.7 \%$ (2/12) of samples from which at least one viral agent was identified. This confirms the previously reported link between BoHV-1 and bovine encephalitis. However, it is the first report on the association of BoHV-1.2b, a putatively less pathogenic BoHV subtype, with neurological disease in cattle.
\end{abstract}

Keywords: bovine herpesvirus type 1, BoHV-1, BoHV-1.2b, rabies, encephalitis

\section{INTRODUÇÃO}

No Brasil, o vírus rábico (VR) é frequentemente reportado como causador de encefalites em bovinos. As perdas associadas à raiva dos herbívoros foram estimadas em cerca de 50 milhões de dólares anuais (King e Turner, 1993). Além da morte do animal infectado pelo VR, a bovinocultura sofre ainda prejuízos devido à espoliação pelos morcegos hematófagos a qual se reflete na diminuição do ganho de peso dos animais e prejuízos à qualidade do couro.

Entretanto, a maioria das encefalites em bovinos permanece sem um diagnóstico definitivo. Com a familiarização dos pesquisadores à

Recebido em 22 de setembro de 2009

Aceito em 10 de setembro de 2010

E-mail: hruthner@yahoo.com.br 
possibilidade do envolvimento de herpesvírus bovinos (BoHVs) em casos de encefalite, estes agentes começaram a ser mais investigados. Em um estudo prévio, os BoHVs foram apontados como a segunda mais frequente causa infecciosa desses quadros em bovinos (Sanches et al., 2000).

Dentre os BoHVs, o BoHV-1 tem sido associado a uma ampla gama de manifestações clínicas em bovinos, particularmente quadros respiratórios e reprodutivos (Riet-Correa, 1989; Roehe et al., 1997) e, eventualmente, encefalites (Roels et al., 2000; Silva et al., 2007b). Buscando associações entre genótipos e sinais clínicos, as amostras de BoHV-1 foram subsequentemente divididas em subtipos (BoHV-1.1 e BHV-1.2). O subtipo 2 foi ainda subdivido em BHV-1.2a e BHV-1.2b, sendo estes associados a diferentes quadros (Rijsewijk et al., 1999). O subtipo 2b é considerado de patogenicidade reduzida (Edwards et al., 1991).

O herpesvírus bovino - 5 (BoHV-5), prevalente no Brasil (Salvador et al., 1998), tem sido primariamente associado a encefalites ou meningoencefalites em bovinos, embora já tenha sido associado a problemas reprodutivos, em alguns casos (Bratanich et al., 1991; Kirkland et al., 2009). As amostras de BoHV-5 foram também subdivididas em subtipos a, b e "não a, não b", ou "c" (D’Arce et al., 2002). Todos os subtipos de BoHV-1 e de BoHV-5 já foram detectados no Brasil (Esteves et al., 2008).

Face à possibilidade da ocorrência de infecções latentes, a associação de herpesvírus com determinada morbidade é caracterizada com mais precisão quando o vírus infeccioso, e não somente DNA viral, é identificado (Ashbaugh et al., 1997).

Em razão disso, no presente estudo buscou-se verificar a incidência de BoHVs em encéfalos de bovinos submetidos ao diagnóstico de raiva no estado do Rio Grande do Sul durante dois anos, estendendo a caracterização das amostras de BoHV isoladas até a determinação de subtipos.

\section{MATERIAL E MÉTODOS}

Foram utilizadas 70 amostras de tecido encefálico de bovinos, enviadas à FEPAGRO Sanidade Animal - IPVDF, compreendendo todas as amostras de origem bovina submetidas ao diagnóstico de raiva deste laboratório durante dois anos consecutivos, 2003 e 2004, provenientes de diversos municípios do estado do Rio Grande do Sul (RS). Como a totalidade do diagnóstico oficial de raiva do estado é processada nesse laboratório, essa amostragem é altamente significativa em relação ao número de amostras submetidas ao diagnóstico de raiva no RS (Teixeira et al., 2008).

Todas as amostras foram submetidas ao diagnóstico de raiva pela técnica de imunofluorescência direta (IFD), de acordo com métodos padronizados usuais (Dean et al., 1996), e também submetidas a protocolos-padrão de inoculação intracerebral em camundongos (Koprowski, 1996).

A caracterização antigênica das amostras positivas para raiva foi realizada por meio da técnica imunofluorescência indireta (IFI) sobre impressões de tecido nervoso, frente a um painel de 12 anticorpos monoclonais (AcMs), produzidos contra antígenos da nucleoproteína do vírus rábico (Batista et al., 2008).

Fragmentos dos encéfalos bovinos foram armazenados $\mathrm{a}-70^{\circ} \mathrm{C}$ até o processamento para o isolamento de BoHVs. O procedimento para isolamento foi realizado como se segue: suspensões a 10\% de um "pool" de tecidos encefálicos foram preparadas em meio mínimo essencial de Eagle (E-MEM), sem soro fetal bovino (SFB), com concentração de antibióticos 10 vezes superior à usual em cultivos celulares (ATB 10X: penicilina $1000 \mathrm{UI} / \mathrm{mL}$; estreptomicina $1000 \mu \mathrm{g} / \mathrm{mL}$ ). As suspensões foram clarificadas por centrifugação a baixa velocidade. O sobrenadante foi inoculado em células Madin Darby Bovine Kidney (MDBK), livres de herpesvírus e pestivírus bovinos, e com $10 \%$ de soro fetal bovino (SFB), livre de anticorpos para herpesvírus e pestivírus. Após adsorção por uma hora a $37^{\circ} \mathrm{C}$, o tapete celular foi lavado, e as células recobertas com E-MEM sem SFB, com ATB 5X. Os cultivos foram monitorados diariamente em busca do efeito citopatogênico (ECP) característico. Cada amostra foi submetida a três passagens sucessivas. Cultivos contendo células-controle não infectadas foram incluídos em todas as passagens. As amostras que não apresentaram 
ECP após a terceira inoculação foram consideradas negativas.

As amostras isoladas foram submetidas ao teste de imunoperoxidase (IPX) como descrito previamente (Roehe et al., 1997). Os anticorpos monoclonais (AcMs) utilizados como anticorpo primário na IPX foram produzidos contra antígenos das glicoproteínas C (gC), E (gE) e I (gI) dos herpesvírus (Rijsewijk et al., 1999, 2000; van Oirschot et al., 1997). Como anticorpo secundário, foi utilizado um conjugado anti-IgG de camundongo/peroxidase (Dako). Outras três amostras de BoHVs foram incluídas na caracterização antigênica para comparação (EVI 123/98, EVI 340/96 e A663; amostras-controle).

O DNA viral das amostras isoladas foi extraído e submetido à analise com endonucleases de restrição (REA). Para tanto, foram utilizadas as enzimas Bam HI e Hind III. Posteriormente, foi realizada eletroforese em gel de agarose a $0.5 \%$, e tal gel foi corado com brometo de etídio e visualizado. As amostras foram classificadas de acordo com os perfis de arranjo genômico conforme D'Arce et al. (2002).

\section{RESULTADOS E DISCUSSÃO}

Das 70 amostras examinadas, foram identificados agentes virais em $12(17,1 \%)$, sendo 11 amostras positivas para raiva. $\mathrm{O}$ perfil antigênico de todas as 11 amostras de VR isoladas foi compatível com aquele usualmente detectado em amostras isoladas de morcegos hematófagos. Tal resultado não representa fato novo, pois as variantes originárias de morcegos hematófagos são as mais frequentemente detectadas em bovinos infectados (Batista et al., 2007).

O BoHV-1 foi isolado de dois encéfalos, representando 2,9\% do total de encéfalos examinados. Entretanto, das 12 amostras de tecido nervoso que evidenciaram a presença de pelo menos um vírus, duas $(16,7 \%)$ foram positivas para herpesvírus bovinos. Uma das amostras positivas para BoHV-1 foi também positiva para raiva. A caracterização antigênica das amostras de BoHV-1 com anticorpos monoclonais (Tab. 1), complementada pela análise genômica por REA, permitiu a determinação dos subtipos dessas amostras (Fig. 1). Uma delas (PG 1779/03) foi classificada como pertencente ao subtipo 2b (BoHV-1.2b), e a outra (PG2560/03) ao subtipo 1 (BoHV-1.1) (Fig. 1). Esta última foi isolada do encéfalo bovino que foi também positivo para raiva.

Igualmente digno de nota é o fato de que as duas amostras isoladas eram do tipo 1, e não do tipo 5 , este último mais frequentemente associado a encefalites (Salvador et al., 1998). Estes achados endossam o envolvimento do BoHV-1 em quadros de encefalites, como já observado por Silva (2007a) e Roels et al. (2000). Portanto, o simples isolamento de BoHVs em casos de encefalite não é suficiente para permitir uma presuntiva tipificação do vírus envolvido, sendo necessários testes complementares para uma tipificação/subtipificação apropriada.

Tabela 1. Perfil de reatividade frente a um painel de anticorpos monoclonais (AcMs) anti-herpesvírus bovinos e diagnóstico de raiva nas amostras isoladas e nas amostras-controle

\begin{tabular}{|c|c|c|c|c|c|c|c|}
\hline \multirow{2}{*}{ Amostra } & \multirow{2}{*}{ Tipo do vírus } & \multirow{2}{*}{ Raiva $^{\#}$} & \multicolumn{5}{|c|}{ AcMs } \\
\hline & & & 3 & 51 & 71 & 77 & 108 \\
\hline PG 1779/03 & BoHV-1.2b & Negativo & - & + & - & - & + \\
\hline PG 2560/03 & BoHV-1.1 & Positivo & + & + & + & + & + \\
\hline EVI 123/98* & BoHV-1.1 & Negativo & + & + & + & + & + \\
\hline EVI 340/96* & BoHV-5a & Positivo & + & + & - & - & + \\
\hline$A 663 *$ & BoHV-5b & Negativo & + & + & - & - & + \\
\hline
\end{tabular}

\#Diagnóstico de raiva realizado por meio de imunofluorescência direta e inoculação em camundongos lactentes.

*Amostras incluídas como controle. 


\section{Batista et al.}

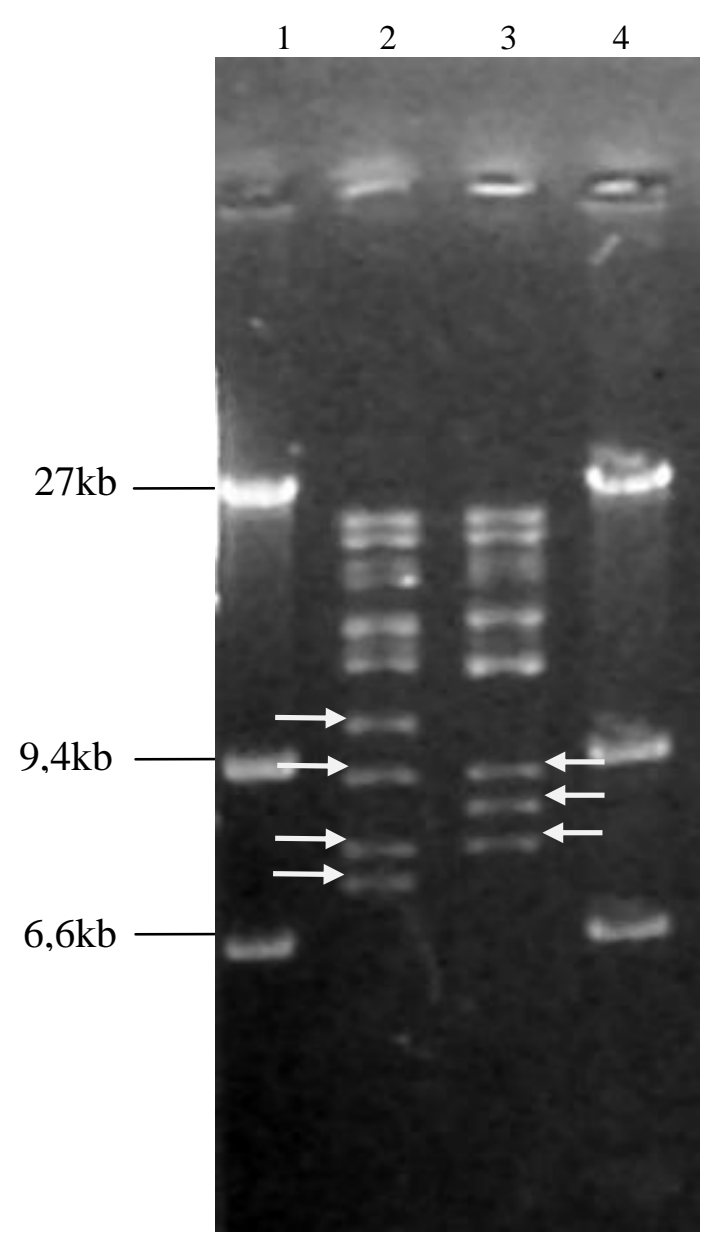

Figura 1. Análise com enzimas de restrição do DNA das amostras de herpesvírus bovinos (BoHVs) isoladas de encéfalos de bovinos. Enzima utilizada: Hind III. Colunas 1 e 4: marcador de peso molecular. Coluna 2: amostra PG 1779/03 (BoHV-1.2b). Coluna 3: amostra PG 2560/03 (BoHV-1.1). As diferenças nos perfis dos subtipos estão salientadas pelas setas.

Estes resultados contrastam com os obtidos em levantamento realizado no estado do Rio de Janeiro, onde os BoHVs foram identificado em 27\% de 146 amostras de tecido encefálico examinadas (Pinto et al., 2003). Além disso, naquele estudo foram identificadas somente amostras de BoHV-5, ao passo que as duas amostras de BoHVs aqui isolados pertenciam ao tipo 1. Estes dados indicam que, na região abrangida pelo estudo de Pinto et al. (2003), a incidência de casos de encefalite por BoHVs foi mais elevada. Este fato, que chama a atenção pelo contraste nas observações reportadas, deve ser objeto de maiores investigações no futuro.

Neste estudo, não foi efetuada a amplificação de DNA viral nos tecidos examinados, a fim de evitar a possibilidade de detecção de DNA de vírus em estado latente. Portanto, as duas amostras de BoHV-1 identificadas de fato correspondem a vírus infeccioso. Recentemente foi identificada alta prevalência de DNA viral em gânglios trigêmeos de bovinos de matadouro, revelando que a presença de DNA viral em tecido nervoso é muito frequente, embora não corresponda à detecção de vírus infeccioso (Campos et al., 2009). Em infecções experimentais com o BoHV-5, DNA viral associado a infecções latentes foi identificado inclusive em sítios extraganglionares (Vogel et al., 2003). Por esse motivo, buscou-se no presente estudo identificar unicamente a presença de vírus infeccioso, o que levou à identificação das duas amostras de BoHV-1. 
Em relação à subtipagem das amostras, é importante salientar que, no Brasil, poucas amostras de BoHVs foram, até o presente, classificadas até subtipo (D'Arce et al., 2002; Esteves et al., 2008). As duas amostras isoladas foram classificadas como BoHV-1.1 (PG2560/03) e BoHV-1.2b (PG 1779/03). O subtipo 1 (BHV-1.1) inclui amostras que causam a forma clássica de infecção respiratória, denominada rinotraqueíte infecciosa bovina (IBR), e lesões genitais (vulvovaginite pustular infecciosa, ou IPV; balanopostite infecciosa ou IPB); as amostras do subtipo 2a (BHV-1.2a) referem-se a vírus associados tanto a IBR/IPV como a abortos, enquanto o subtipo $2 \mathrm{~b}$ (BHV$1.2 b)$ tem sido associado a amostras que causam IPV/IPB, mas que não causam abortos (Engels e Ackermann, 1996). O subtipo 2 b já foi detectado na Austrália e na Europa, e é considerado menos patogênico (Edwards et al., 1991; Australian..., 2005). Não obstante, uma das amostras aqui identificadas pertence ao subtipo $2 b$ e foi detectada em um caso de encefalite. Que seja do conhecimento dos autores: esse é o primeiro relato de associação do subtipo $2 b \quad$ com encefalites. Este achado põe em dúvida a prerrogativa de que o subtipo $2 \mathrm{~b}$ seria menos patogênico. Por outro lado, não se pode excluir a possibilidade de o animal haver sofrido infecção com outro (ou outros) herpesvírus relacionado(s) ao quadro de encefalite, o qual não foi, por alguma razão, diagnosticado no presente trabalho. Infecções com mais de um herpesvírus são frequentes no estado (Campos et al., 2009). A amostra de BoHV-1.2b isolada no decorrer do presente estudo deve ser alvo de estudos futuros, para que seja possível avaliar seu potencial patogênico e sua importância para a pecuária do país.

Em relação à detecção de vírus rábico e BoHV-1 em um mesmo animal, é interessante observar que esse tipo de achado não é frequente. Sabe-se que já foi descrito um caso de infecção concomitante com BoHV-5 e vírus rábico (Spilki et al., 2003). Entretanto, até o presente, esses autores ainda não haviam identificado $\mathrm{BoHV}-1$ em encéfalos de bovinos suspeitos de raiva. Face à ocorrência de infecções latentes, detectadas com elevada prevalência no Rio Grande do Sul (Campos et al., 2009), poder-se-ia esperar que uma infecção aguda intercorrente com o vírus rábico pudesse ser um fator desencadeante para a reativação de uma infecção por herpesvírus. Isso, entretanto, não parece ter sido o caso no presente estudo. É interessante observar que, apesar da alta incidência de infecções latentes reportada por Campos et al. (2009) no estado, a incidência de encefalites causadas pelo vírus rábico com evidente reativação de BoHVs parece ser baixa, sugerindo que a raiva não desempenha papel significativo na reativação de BoHVs.

\section{AGRADECIMENTOS}

Trabalho realizado com recursos da FEPAGRO e CNPq. P.M. Roehe é pesquisador $1 \mathrm{C}$ do CNPq. F.R. Spilki é pesquisador 2 do $\mathrm{CNPq}$.

\section{REFERÊNCIAS BIBLIOGRÁFICAS}

ASHBAUGH, S.E.; THOMPSON, K.E.; BELKNAP, E.B. et al. Specific detection of shedding and latency of bovine herpesvirus 1 and 5 using a nested polymerase chain reaction. J. Vet. Diagn. Invest., v.4, p.387-394, 1997.

AUSTRALIAN GOVERNMENT - The biology of bovine herpesvirus 1 (BoHV-1). Canberra: Department of Health and Ageing - Office of the Gene Technology Regulator, 2005. p.1-24.

BATISTA, H.B.C.R.; FRANCO, A.C.; ROEHE, P.M. Raiva: uma breve revisão. Acta Scient. Vet., v.35, p.125-144, 2007.

BATISTA, H.B.C.R.; SCHMIDT, E.; TEIXEIRA, T.F. et al. Caracterização antigênica de amostras do vírus da raiva isoladas nas regiões Norte e CentroOeste do Brasil com anticorpos monoclonais antilissavírus. Arq. Bras. Med. Vet. Zootec., v.60, p.260-262, 2008.

BRATANICH, A.C.; SARDI, S.I.; SMITSAART, E.N. et al. Comparative studies of BHV-1 variants by in vivo - in vitro tests. Zentralbl. Veterinarmed. B., v.38, p.41-48, 1991.

CAMPOS, F.S.; FRANCO, A.C.; HÜBNER, S.O. et al. High prevalence of coinfections with Bovine herpesvirus 1 and 5 found in cattle in southern Brazil. Vet. Microbiol., v.139, p.67-73, 2009.

D'ARCE, R.C.F.; ALMEIDA, R.S.; SILVA, T.C. et al. Restriction endonuclease and monoclonal antibody analysis of Brazilian isolates of bovine herpesvíruses types 1 and 5. Vet. Microbiol., v.88, p.315-324, 2002.

DEAN, D.J.; ABELSETH, M.K.; ATHANASIU, P. et al. The Fluorescent antibody test. In: MESLIN, F.-X.; KAPLAN, M.M.; KOPROWSKI, H. (Eds). Laboratory techniques in rabies. 4.ed. Geneva: WHO, 1996. p.88-93. 
EDWARDS, S.; NEWMAN, R.H.; WHITE, H. The virulence of British isolates of bovid herpesvirus 1 in relationship to viral genotype. Br. Vet. J., v.147, p.216-231, 1991

ENGELS, M.; ACKERMANN, M. Pathogenesis of ruminant herpesvirus infections. Vet. Microbiol., v.53, p.3-15, 1996.

ESTEVES, P.A.; DELLAGOSTIN, O.A.; PINTO, L.S. et al. Phylogenetic comparison of the carboxyterminal region of glycoprotein $\mathrm{C}(\mathrm{gC})$ of bovine herpesviruses (BoHV) 1.1, 1.2 and 5 from South America (SA). Virus Res., v.131, p.16-22, 2008.

KING, A.A.; TURNER, G.S. Rabies: A review. $J$. Comp. Pathol., v.108, p.1-39, 1993.

KIRKLAND, P.D.; POYNTING, A.J.; GU, X. et al. Infertility and venereal disease in cattle inseminated with semen containing bovine herpesvirus type 5 . Vet. Rec., v.165, p.111-113, 2009.

KOPROWSKI, H. The mouse inoculation test. In: MESLIN, F.X.; KAPLAN, M.M.; KOPROWSKI, H. (Eds). Laboratory techniques in rabies. 4.ed. Geneva: WHO, 1996. p.80-86.

PINTO, A.M.V.; ROMIJN, P.C.; SILVA, R.C.F. et al. Geographic distribution of BHV-5 in Rio de Janeiro state. In: NATIONAL MEETING OF VIROLOGY, 14., 2003, Florianópolis. Anais... São Paulo: Sociedade Brasileira de Virologia, 2003. p.141.

RIET-CORREA, F.; VIDOR, T.; SCHILD, A.L. et al. Meningoencefalite e necrose do córtex cerebral em bovinos causadas por herpesvírus bovino-1. Pesq. Vet. Bras., v.9, p.13-16, 1989.

RIJSEWIJK, F.A.M.; KAASHOEK, M.J.; LANGEVELD, J.P. et al. Epitopes on glycoprotein C of bovine herpesvírus-1 (BHV-1) that allow differentiation between BHV-1.1 and BHV-1.2 strains. J. Gen. Virol., v.80, p.1477-1483, 1999.

RIJSEWIJK, F.A.M.; KAASHOEK, M.J.; LANGEVELD, J.P. et al. Epitopes on glycoprotein E and on the glycoprotein E/glycoprotein I complex of bovine herpesvírus 1 are expressed by all of 222 isolates and 11 vaccine strains. Arch. Virol., v.145, p.921-936, 2000 .

ROEHE, P.M.; SILVA, T.C.; NARDI, N.B. et al. Diferenciação entre os vírus da rinotraqueíte infecciosa bovina e herpesvírus da encefalite bovina com anticorpos monoclonais. Pesq. Vet. Bras., v.17, p.41-44, 1997.
ROELS, S.; CHARLIER, G.; LETELLIER, C. et al. Natural case of bovine herpesvirus 1 meningoencephalitis in an adult cow. Vet. Rec., v.146, p.586-588, 2000.

SALVADOR, S.W.C.; LEMOS, R.A.A.; RIETCORREA, F. et al. Meningoencefalite em bovinos causada por herpesvírus bovino-5 no Mato Grosso do Sul e São Paulo. Pesq. Vet. Bras., v.18, p.76-83, 1998.

SANCHES, A.W.D.; LANGOHR, I.M.; STIGGER, A.L. et al. Doenças do sistema nervoso central em bovinos no Sul do Brasil. Pesq. Vet. Bras., v.20, p.113-118, 2000.

SILVA, MS.; BRUM, M.C.; LORETO, E.L. et al. Molecular and antigenic characterization of Brazilian bovine herpesvírus type 1 isolates recovered from the brain of cattle with neurological disease. Virus Res., v.129, p.191-199, 2007a.

SILVA, M.S.; BRUM, M.C.; WEIBLEN, R. et al. Identificação e diferenciação de herpesvírus bovino tipos 1 e 5 isolados de amostras clínicas no Centro-Sul do Brasil, Argentina e Uruguai (1987-2006). Pesq. Vet. Bras., v.27, p.403-408, 2007b.

SPILKI, F.R.; FRANCO, A.C.; TEIXEIRA, M.B. et al. Bovine herpesvírus type 5 (BHV-5) in a calf with rabies 1. Pesq. Vet. Bras., v.23, p.1-4, 2003.

TEIXEIRA, T.F.; HOLZ, C.L.; CAIXETA, S.P.M.B. et al. Diagnóstico de raiva no Rio Grande do Sul, Brasil, de 1985 a 2007. Pesq. Vet. Bras., v.28, p.515520, 2008.

VAN OIRSCHOT, J.T.; KAASHOEK, M.J.; MARISVELDHUIS, M.A. et al. An enzyme-linked immunosorbent assay to detect antibodies against glycoprotein $\mathrm{gE}$ of bovine herpesvírus 1 allows differentiation between infected and vaccinated cattle. J. Virol. Methods, v.67, p.23-34, 1997.

VOGEL, F.S.F.; CARON, L.; FLORES, E.F.F. et al. Distribution of bovine herpesvirus type 5 DNA in the central nervous systems of latently, experimentally infected calves. J. Clin. Microbiol., v.41, p.4512-4520, 2003. 